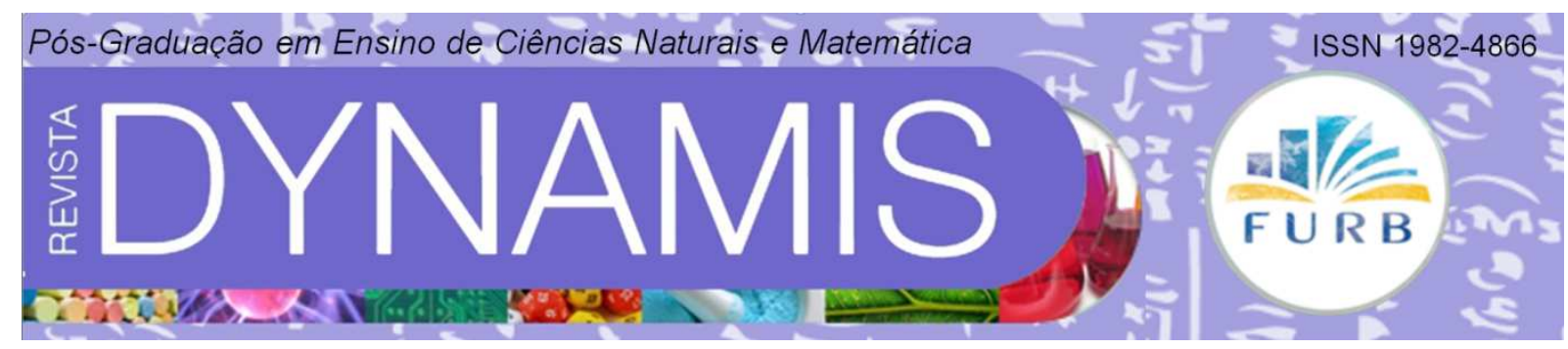

\title{
O USO DE SOFTWARES, TABELAS E PLANILHAS NAS PRÁTICAS LABORAIS DE ENGENHEIROS
}

The use of software, tables and spreadsheets in industrial practices of engineers

Márcia Jussara Hepp Rehfeldt

Centro de Ciências Exatas e Tecnológicas

Centro Universitário UNIVATES

mrehfeld@univates.br

Cristiane Antonia Hauschild

Centro de Ciências Exatas e Tecnológicas

Centro Universitário UNIVATES

crishauschild@univates.br

Marli Teresinha Quartieri

Centro de Ciências Exatas e Tecnológicas

Centro Universitário UNIVATES

mtquartieri@univates.br

leda Maria Giongo

Centro de Ciências Exatas e Tecnológicas

Centro Universitário UNIVATES

igiongo@univates.br

Karina Corbellini Brito de Azambuja Centro de Ciências Exatas e Tecnológicas

Centro Universitário UNIVATES

kazambuja@univates.br 


\title{
Resumo
}

Este artigo tem por objetivo apresentar resultados parciais da pesquisa "Formas de vida, jogos de linguagem e currículo: implicações para o ensino de engenharia", em desenvolvimento num Centro Universitário, localizado no sul do Brasil. Assim, tem-se o intuito de socializar depoimentos de um grupo de engenheiros sobre como usam a matemática para resolver situações-problemas do cotidiano. Como aporte teórico foram usadas obras de Bazzo e Pereira (2008), Timm (2005) e Kipper (2014). Metodologicamente caracteriza-se como um estudo qualitativo. As informações foram obtidas por meio de entrevistas gravadas e transcritas, realizadas com cerca de trinta engenheiros, que posteriormente foram categorizadas. Uma destas categorias, discutida neste artigo, mostra que estes profissionais fazem uso de softwares, de tabelas e de planilhas. Estes recursos auxiliam os profissionais facilitando cálculos matemáticos complexos, reduzindo o tempo de elaboração e criação de projetos, bem como auxiliando no gerenciamento de atividades no âmbito da gestão.

Palavras-chave: Práticas laborais. Engenheiros. Recursos tecnológicos.

\begin{abstract}
This article aims to present partial results of the research "Life forms, language games and curriculum: implications for engineering teaching", in development at a University Center, located in south of Brazil. There is the intention to socialize lines of a group of engineers about how they use math to solve real-world problem-situations. The theoretical basis lies on Bazzo and Pereira (2008), Timm (2005) and Kipper (2014). Methodologically it is characterized as a qualitative study. The information were obtained through recorded and transcribed interviews carried out with about thirty engineers who were later categorized. One of these categories, discussed in this article shows that these professionals make use of software, tables and spreadsheets. These resources help the professionals facilitate complex mathematical calculations, reducing the time of elaboration and creation of projects, as well as assisting in the management of activities in the management.
\end{abstract}

Keywords: Labor practices. Engineers. Technological resources. 


\section{INTRODUÇÃO}

A formação de profissionais na área da engenharia tem sido foco de estudo de pesquisadores e professores e está sendo amplamente discutida em eventos como o Congresso Brasileiro de Educação em Engenharia (COBENGE). Tais estudos justificam-se uma vez que se observa um aumento no número de profissionais que se gradua a cada ano, bem como um incremento na demanda por esses profissionais. Segundo Borges e Almeida (2013), o país titulou, em 2011, em torno de 45.000 estudantes na área da engenharia. No entanto, segundo informações do diretor da Escola de Engenharia Mauá Marcello Nitz (INFOMAUÁ, 2012), embasado num estudo Instituto de Pesquisa Econômica Aplicada (IPEA), "até 2020 o Brasil terá de formar em torno de 95 mil engenheiros por ano para sustentar um crescimento econômico anual de 4\%." Corroborando com estas afirmações, Oliveira et al (2013, p. 4) argumentam que "a média anual de crescimento do número de concluintes saltou de aproximadamente 5\% na década de 1990 para cerca de $10 \%$ nos últimos 10 anos". No entanto, o número de graduados não é suficiente para atender esta previsão de demanda. Ainda segundo os autores, se observou um aumento no número de modalidades de Engenharia, bem como algumas alterações de enfoque. Comentam os autores:

\footnotetext{
$\mathrm{Na}$ ampliação do espectro de abrangência da Engenharia, verifica-se que a implementação de conteúdos relacionados à automação e computação em cursos, ou mesmo a criação de novos cursos no ITA (Instituto Tecnológico da Aeronáutica) e na USP (Universidade de São Paulo), no início da década de 1950, pode ser considerada como o marco inicial desse novo enfoque - Novas Tecnologias - dos cursos de Engenharia no Brasil (OLIVEIRA, 2006 apud OLIVEIRA et al, 2013, p. $10)$.
}

Ainda segundo os autores supracitados, além deste enfoque tecnológico da engenharia há outro oriundo de modalidades relacionadas às questões Ambientais e de Saúde (Engenharia Ambiental, de Alimentos, Sanitária, entre outras). Para eles:

Paradoxalmente, estas Engenharias surgem em decorrência dos problemas criados
em função da maior exploração dos recursos naturais do planeta e da emissão de
poluentes pelas indústrias, além da necessidade de reaproveitamento ou reciclagem
de produtos descartados. Isto ocorre, evidentemente, devido ao desenvolvimento
tecnológico, que torna cada vez mais sofisticada a transformação de recursos em
bens - que, por sua vez, geram dejetos poluentes lançados na natureza, tanto na sua
fabricação quanto no seu uso e descarte (OLIVEIRA et al, 2013, p. 10).

De acordo com Borges e Almeida (2013), para dar conta desta demanda, novas escolas de engenharia surgem e documentam, por meio dos seus projetos pedagógicos, um perfil de egresso que depende da cultura, da tradição de oferta de cursos, do engajamento na pesquisa científica e tecnológica e de outros aspectos relacionados à economia do país, à inserção regional e às demandas do setor empresarial. Em adição mencionam os autores:

A grande velocidade dos avanços tecnológicos, acrescida dos grandes desafios econômicos e sociais resultam na permanente necessidade de atualização curricular. Assim, o planejamento, a elaboração e a oferta dos cursos de engenharia, bem como o perfil do profissional buscado pelo setor empresarial, caracterizam um notável desafio para a academia (BORGES; ALMEIDA, 2013, p. 1).

Oliveira et al (2013, p. 1) também comentam que o desafio na formação destes profissionais está no ensino com qualidade e para que isso ocorra é necessário "que se invista 
na formação do corpo docente [...] e na modernização de projetos pedagógicos e da infraestrutura de funcionamento destes cursos".

Levando em consideração os aspectos relacionados à formação dos profissionais engenheiros acima mencionados, e à formulação do currículo, um grupo de professores do Centro Universitário UNIVATES, localizado no Vale do Taquari, estado do Rio Grande do Sul está desenvolvendo uma pesquisa que pretende investigar como os engenheiros do Vale do Taquari usam a matemática para resolver situações-problema cotidianas. Atualmente, o estudo conta com o apoio da Fundação de Amparo à Pesquisa do Estado do Rio Grande do Sul (FAPERGS). Supõe-se que tais resultados possam promover mudanças curriculares, em especial no que tange à metodologia de ensino da Matemática em disciplinas como Introdução às Ciências Exatas, Cálculos I, II e III e Cálculo Numérico na referida Instituição. Para alcançar o objetivo acima citado, o grupo de professores entrevistou engenheiros em seus locais de trabalhos sendo estas entrevistas gravadas, transcritas e categorizadas. Uma destas categorias, discutida neste artigo, mostra que estes profissionais fazem uso de softwares, de tabelas e de planilhas.

\section{REVISÃO DA LITERATURA}

Segundo Timm (2005), as necessidades do ensino de engenharia no mundo contemporâneo devem levar em consideração: o estímulo ao espírito prático, o raciocínio científico, uma metodologia baseada na estratégia de resolução de problemas, o trabalho em equipe, a curiosidade, a visão sistêmica, a noção de gestão, a comunicabilidade, a visão globalizada, a flexibilidade cultural e as responsabilidades ambiental e social. A autora ainda salienta que é necessário manter a qualidade e características históricas e agregar novas exigências da cultura do século XXI, bem como novas práticas pedagógicas e tecnologias educacionais.

Castro, Caveiro e Oliveira (2001) e Militisky (1998 apud TIMM 2005) argumentam que a característica mais comum nos cursos de engenharia é uma formação prioritariamente técnica e científica, embasada num método de ensino de transmissão de conhecimentos, mas insuficiente frente às demandas e grandes transformações da sociedade, da economia e da tecnologia do final do século XX.

A partir dos excertos dos autores supracitados pode-se inferir que estamos diante de uma mudança emergente no currículo das engenharias, com a inclusão de práticas pedagógicas que contemplem tecnologias, flexibilidade cultural, responsabilidades ambiental e social, entre outros aspectos, além da formação técnica e científica, intrínseca ao engenheiro. No entanto, de acordo com Borges e Almeida (2013), os currículos dos cursos de engenharia pouco mudaram desde a década de 70 . Mencionam os autores:

Isso representa, para os educadores da área, alguns problemas fundamentais que têm permanecido sem solução, no que tange ao planejamento, elaboração e implementação dos cursos de graduação em engenharia com vista a adequar tais cursos ao cenário vigente, assim como sua interação com o exercício desse profissional. É preciso enfrentar este desafio de forma rápida e eficaz. Essa questão vem sendo discutida pela comunidade de engenharia há décadas e sempre se depara com a necessidade de modernização dos cursos de engenharia no País. Isso inclui necessariamente a qualificação dos docentes que atuam na educação em engenharia. Se por um lado tais profissionais têm sido cada vez mais bem formados em suas áreas de atuação, por outro ainda carecem de formação pedagógica compatível com 
a responsabilidade de formar os engenheiros do século XXI (BORGES; ALMEIDA, 2013, p. 2).

Hattum, Oliveira e Williams (2013) projetando o futuro do ensino da engenharia comentam que nos Estados Unidos a National Academy of Engineering está refletindo sobre a formação de engenheiros para o ano 2020. Segundo os autores, as mudanças que os futuros engenheiros enfrentarão (velocidade da evolução tecnológica, crescimento da população mundial que utilizará os recursos naturais existentes, deslocalização das áreas rurais para as áreas urbanas, aumento da esperança média de vida) implicarão tanto no sistema de saúde quanto nos recursos naturais. Tais aspectos também precisam estar contemplados e ser discutidos no currículo dos engenheiros.

Para alguns autores poucas mudanças foram contempladas nos currículos e, portanto na sala de aula. No entanto, pequenas transformações, em especial, no que diz respeito à forma de atuação do engenheiro foram percebidas. Timm (2005), por exemplo, argumenta que uma modificação percebida na atuação do engenheiro nos últimos anos foi a inserção do computador nas práticas laborais. Menciona a autora:

\begin{abstract}
Mudanças foram provocadas pelo uso massificado do computador na prática de Engenharia, como os softwares de cálculos e os de simulações, que aumentaram as condições de controle, previsibilidade, precisão e outros elementos intrínsecos ao fazer profissional do engenheiro. Passaram a ser, portanto, indispensáveis na formação dos engenheiros, em maior ou menor intensidade, dependendo dos recursos da instituição (TIMM, 2005, p. 152).
\end{abstract}

Bermudez (1999) já afirmava que os avanços tecnológicos são cada vez mais rápidos. Em adição menciona o autor: "A informática, a automação, a tecnologia de materiais e o nível de atual industrialização da sociedade mundial reduziram a semanas o tempo necessário para converter-se uma simples ideia em um produto acabado" (BERMUDEZ, 1999, p. 68). De forma similar, Silva (1999) comenta que os engenheiros dos anos 1990 são mais hábeis nas ferramentas computacionais e tendem a experimentar muito, realizando simulações do tipo tentativa e erro. Ainda segundo o mesmo autor, diferentemente dos anos 1990, os engenheiros dos anos 1980 tinham uma formação mais sólida nas Ciências Exatas como a Física e a Matemática. No decorrer dos anos, percebe-se, de forma empírica e a partir de pesquisas como a mencionada no início do artigo, um incremento ainda maior no uso de recursos computacionais, tanto na formação do engenheiro quanto nas práticas laborais.

Em adição, cabe mencionar a significativa relação estabelecida entre a informática e a engenharia. Loder e Bender (2007) comentam que a engenharia é uma das áreas que mais contribuiu tanto no surgimento da informática quanto no seu desenvolvimento e isso se reflete no uso que estes profissionais fazem dela, tanto em sala de aula quanto no local de trabalho. Afirmam as autoras:

[...] é previsível que, na Engenharia, o campo de aplicação da Informática permaneça próspero e seja cada vez mais abrangente. A presença massiva da Informática nas aplicações em engenharia tem se refletido de várias formas, desde o chão de fábrica, com a presença cada vez maior de sistemas automatizados (CAM - Computer Aided Manufacturing), até a prancheta do engenheiro, nas atividades de projeto (CAD Computer Aided Design), através do uso dos mais variados tipos de programas de computadores (softwares). Da mesma forma, como causa e, simultaneamente, como consequência dessa situação verificada no mundo do trabalho, a Informática tem es- 
tado presente nas atividades acadêmicas de estudantes e de professores de engenharia. (LODER; BENDER, 2007)

No que tange ao uso de softwares em sala de aula, várias instituições têm utilizado estes recursos na formação de profissionais da área da Engenharia. Farias, Oliveira e Junior (2014, p. 1) abordam num estudo realizado na Universidade de Brasília a importância do uso dos softwares MatLab e Pspice e afirmam que eles "são de extrema importância para o aprendizado de circuitos elétricos, pois as simulações facilitam a visualização dos teoremas estudados na referida disciplina”. Já na Universidade Federal de Goiás, segundo Cabral et al (2013), os softwares mais utilizados nos cursos de engenharia são MATLAB, OrCAD PSpice, LabVIEW e PSIM. Para os autores

\begin{abstract}
Ao utilizar as ferramentas de software o aluno consegue colocar em prática o seu conhecimento. Em disciplinas puramente teóricas, o software enriquece o aprendizado, pois permite o exercício dos conceitos vistos em sala. Em disciplinas com parte prática é quase imprescindível, pois o uso do software geralmente viabiliza a simulação das experiências realizadas e a agilidade nos cálculos necessários em ambiente de laboratório (CABRAL et al, 2013, p. 8).
\end{abstract}

Ainda concorda-se com Lima, Neto e Araújo Junior (2013, p. 1) quando estes mencionam que "na vida profissional de um engenheiro, a previsão e controle de processos dentro de plantas industriais por [...] softwares é capaz de minimizar custos e otimizar tais processos". Portanto, conforme Booth, Sauer e Lima (2011 apud PEREIRA et al 2014, p. 4),

\begin{abstract}
capacitar o engenheiro a "aprender a aprender" e a atuar em seu meio profissional com competência são objetivos que devem orientar os rumos do processo educativo de sua formação. Parece estar cada vez mais evidente que qualquer remodelação na educação tecnológica deve ser realizada com a inclusão de estudos que provoquem análises críticas entre ciência, tecnologia e sociedade para que, além de profissionais competentes em suas habilidades específicas haja a possibilidade de formar cidadãos comprometidos com o desenvolvimento econômico e ambientalmente sustentável da sociedade $[\ldots]$.
\end{abstract}

Com vistas a observar o uso da matemática que o engenheiro afirma que faz frente às situações-problema, bem como propor algumas alterações na metodologia de ensino da Matemática nos cursos de Engenharia do Centro Universitário UNIVATES está sendo realizada a pesquisa Formas de vida, jogos de linguagem e currículo: implicações para o ensino de engenharia, cuja metodologia será descrita a seguir.

\title{
3 METODOLOGIA
}

A pesquisa mencionada anteriormente está em desenvolvimento e traz uma abordagem qualitativa. Segundo Silveira e Córdova (2009, p. 33), "a pesquisa qualitativa não se preocupa com representatividade numérica, mas sim, com o aprofundamento de um grupo social, de uma organização". Para os autores, os pesquisadores ao usar este método "buscam explicar o porquê das coisas, exprimindo o que convém ser feito [...] o objetivo da amostra é de produzir informações aprofundadas e ilustrativas" (SILVEIRA; CÓRDOVA, 2009, p. 34). Ainda segundo os autores, as principais características

são objetivação do fenômeno, hierarquização das ações de descrever, compreender, explicar, precisão de relações entre o global e o local em determinado fenômeno; respeito ao caráter interativo entre os objetivos buscados pelos investigadores, suas 
orientações teóricas e seus dados empíricos; busca de resultados os mais fidedignos possíveis; oposição ao pressuposto que defende um modelo único de pesquisa para todas as ciências (SILVEIRA; CÓRDOVA, 2009, p. 34).

Em complemento, Lankshear e Knobel (2008) citam que pesquisadores qualitativos priorizam os dados coletados em ambientes naturais ou da vida real na qual a ação acontece. A observação e coleta de dados ocorrem por meio da observação de práticas reais ou eventos da vida real, de gravações, de entrevistas e de histórias. Para os autores "a pesquisa qualitativa proporciona descrições ricas e detalhadas de pessoas em ação, programas específicos ou práticas sociais" (LANKSHEAR; KNOBEL, 2008, p. 67).

Com este enfoque foram efetivadas entrevistas com mais de trinta engenheiros que atuam em empresas localizadas no Vale do Taquari. Cabe observar que os profissionais responderam as questões em seus locais de trabalho. Entre as perguntas realizadas destacaram-se: a) Quanto aos dados de identificação: formação, tempo de atuação, idade, instituição em se graduação; b) Questões específicas: conteúdos matemáticos utilizados em seu cotidiano, contribuições que a Matemática, em especial, o Cálculo pode dar para a formação do engenheiro e o modo de resolução de problemas matemáticos cotidianos. Também foram realizadas observações e filmagens das atividades laborais dos engenheiros e suas práticas foram acompanhadas em alguns turnos de trabalho. $\mathrm{O}$ objetivo foi verificar como estes profissionais usavam a matemática para solucionar as situações-problema cotidianas.

Os profissionais entrevistados pertencem às áreas de Engenharia Ambiental, Engenharia de Alimentos, Engenharia Civil, Engenharia de Controle e Automação, Engenharia da Computação, Engenharia de Produção e Engenharia Mecânica e foram graduados por diversas universidades do estado do Rio Grande do Sul. O tempo de atuação como engenheiro variou: os menos experientes tinham em torno de 5 anos de prática profissional, já os mais "antigos na profissão" possuíam mais de 20 anos.

$\mathrm{Na}$ análise e interpretação dos resultados deste estudo os engenheiros serão nomeados E1, E2, E3 e assim sucessivamente para preservar o anonimato, conforme previsto no Termo de Consentimento Livre e Esclarecido assinado pelos entrevistados. As entrevistas foram analisadas e classificadas em categorias, conforme sugere Bardin (2011). Segundo o autor "classificar elementos em categorias impõe a investigação do que cada um deles tem em comum com outros. O que vai permitir o seu agrupamento é a parte comum existente entre eles" (BARDIN, 2011, p. 148). Assim, uma das categorias estabelecidas foi o uso que estes profissionais fazem de softwares, de tabelas e de planilhas, e consta na análise dos dados a seguir.

\section{ANÁLISE DOS DADOS}

Uma avaliação inicial e global a partir análise das falas dos engenheiros permite inferir que recursos como softwares, planilhas e tabelas estão efetivamente presentes nas atividades laborais dos entrevistados tendo em vista que eles auxiliam os profissionais facilitando cálculos matemáticos complexos, reduzindo o tempo de elaboração e criação de projetos e nas atividades relacionadas ao gerenciamento da empresa. 
De acordo com o E1, "os engenheiros [...] mais jovens fazem tudo no AutoCAD", referindo-se a um software específico usualmente utilizado na área de Engenharia Civil. Bazzo e Pereira (2008, p. 107) corroboram esta afirmação e mencionam que "praticamente mais nada hoje, na nossa vida cotidiana, é feito sem o auxílio de ferramentas computacionais". Ainda segundo os autores "na engenharia, em todos os seus campos, é inquestionável a sua aplicação [ferramentas computacionais]. Por isso, recomendamos o aprendizado, a atualização constante e o uso frequente do ferramental proporcionado pelos sistemas computacionais, com seus programas e possibilidades de programação" (BAZZO; PEREIRA, 2008, p. 107).

De acordo com E2, que além de engenheiro é professor no curso, o uso computadores permite chegar mais rápido ao resultado. Para elucidar sua fala menciona um exemplo de problema desenvolvido em sala de aula, no qual os alunos dimensionam a estrutura metálica de um carrinho.

Lá nos fizemos através de um software por dois motivos importantes. Na engenharia mecânica, em dois anos, os alunos não foram até Resistência dos Materiais II e também pela complexidade, uma série de curvas das estruturas metálicas. Então é difícil calcular a mão, então a gente faz através do software, informa para o software quais são as dimensões, ou seja, precisa detalhar as dimensões de cada barra (E2).

O engenheiro E1 afirma que os cálculos estruturais não são mais realizados manualmente, destacando que estes complexos cálculos da disciplina de hidráulica, presentes na grade curricular dos cursos de Engenharia Ambiental e Engenharia Civil, são dimensionados hoje em dia no computador. Já o profissional E3 expressa que em seu cotidiano precisa definir a fórmula que melhor se encaixa no comportamento de um gráfico, porém, afirma fazer uso de softwares para identificação deste padrão.

As falas acima mencionadas nos remetem à ideia de que a sociedade moderna está cada vez mais dependente de recursos tecnológicos, tanto em sua vida social quanto em atividades cotidianas. Bazzo e Pereira (2008, p. 83) afirmam que "muito do que as evoluções da ciência e da tecnologia têm proporcionado, nos facilita a vida, economiza tempo [...]". Lima, Neto e Araújo Junior (2013, p. 1) citam "A utilização de softwares de computação numérica vem se expandindo cada vez mais no ramo da engenharia. Estes softwares são práticos e rápidos na resolução de problemas complexos, que são impossíveis ou extremamente dispendiosos para serem solucionados por seres humanos".

Dentre os principais softwares mencionados está o Excel. Segundo os entrevistados, a utilização deste software está fortemente relacionada a atividades gerenciais. Conforme mencionado pelo profissional E4, o software é uma ferramenta indispensável para quem trabalha com gerenciamento de projetos, sendo de extrema importância para lançar planilhas. Neste sentido, concorda-se com Bazzo e Pereira (2008, p. 92) quando estes afirmam que:

A familiarização com a tecnologia requer que o profissional saiba muito de ciências físicas aplicadas e domine conhecimentos empíricos sistematizados. [...] Além dessa familiarização com a tecnologia - seu funcionamento, sua lógica - é fundamental também a familiarização com os resultados e as consequências da utilização das tecnologias no entorno social em que vivemos. 
Silva (1999, p. 85) afirma que "formar um engenheiro não é somente transmitir-lhe conhecimentos técnicos, mas também conscientizá-lo de sua função e responsabilidade perante a sociedade". Dessa forma, ao utilizar ferramentas computacionais, o profissional engenheiro precisa estar ciente que a responsabilidade técnica pela obra, projeto ou produto é sua e não do software. O engenheiro E5 menciona fazer uso de ferramentas computacionais, mas enfatiza: "antes de pagar o software eu tive que assinar um documento que eu assumo totalmente a responsabilidade pelos resultados [...]". E para se certificar, leu o manual de utilização e realizou vários cálculos "à mão" para verificar se o software estava fazendo de forma confiável. Bermudez (1999, p. 72) destaca que um "engenheiro de chão de fábrica não deve apenas saber usar a tecnologia existente. Ao usar uma tecnologia, esse profissional deve ser capaz de questionar sua qualidade do ponto de vista conceitual e de decidir sobre a possibilidade de melhorá-la", destacando que é desse tipo de profissional que mercado de trabalho precisa. Em adição, Bazzo e Pereira (2008, p. 94) afirmam que:

Um engenheiro deve saber distinguir as possíveis fontes de erros, surgidos em função dos aparelhos de medição, das simplificações adotadas quando da realização dos testes, da impossibilidade de uma repetição dos ensaios, da influência do acaso, das incertezas e de uma gama enorme de outros parâmetros.

Tendo em vista a frequente utilização de ferramentas computacionais evidenciada, perguntou-se aos engenheiros quanto à necessidade de conhecimentos teóricos para manuseamento destes programas. Para E6, o computador realiza os cálculos, mas é o profissional quem precisa dizer para o computador como é que se calcula. Segundo E4, o software ajuda em suas atividades diárias, mas não substitui o profissional: "o AutoCAD calcula tudo, mas no momento que tu estás conversando com uma pessoa, tu tens que saber pelo menos fazer um cálculo de volume" (E4). Além disso, os profissionais de forma geral mencionam que os softwares estão cada vez mais sendo utilizados para finalizar projetos, entretanto, é importante que os dados lançados nestes programas computacionais sejam revisados, evitando possíveis erros. Ainda o engenheiro E4 menciona que o software é uma máquina que não pensa, e sim resolve problemas determinados por comandos, e por isto, é necessário realizar revisões e conhecer os processos de resolução.

\footnotetext{
Eu vejo ele [software] como uma ferramenta, claro que é importante que ele [profissional] tenha esse conhecimento antes para poder operar essa ferramenta, mas também o profissional tem que entrar depois que o software termina e avaliar esse projeto. Por que o computador vai entregar uma coisa da forma como ele determinou e às vezes ele determina uma situação que o software não entendeu, então ele tem que entrar no manual e corrigir (E4).
}

O profissional E7 afirma que o aluno do curso de engenharia de produção "precisa ter uma ideia de quais são as equações que precisam ser colocadas dentro de um software para este software dar uma série de respostas". O engenheiro E8 menciona que "cálculo mesmo, a gente tem que saber que ele existe, mas normalmente tudo já é tabelado". Segundo E9, o uso manual de conteúdos matemáticos no cotidiano de um engenheiro de controle e automação é mínimo, enfatizando que,

[Os profissionais] que são do desenvolvimento de produtos e de processos [...], eles não vão pegar no papel e vão ficar deduzindo, eles vão ter o software, mas quem não passou por uma dedução manual, não entendeu algoritmo do cálculo, não vai conseguir nem entender o que o simulador está produzindo como resposta (E9). 
Silva (1999, p. 85) menciona que "no mundo de novos conhecimentos e serviços, líderes na área tecnológica devem entender de negócios tão bem quanto de tecnologia". Ainda segundo o autor, "os produtos tecnológicos de mais alto valor agregado são particularmente dependentes das habilidades do engenheiro líder: formulando estratégias de negócios, motivando, treinando e criando organizações capazes de vencer no mercado de trabalho" (Silva, 1999, p. 85). Em síntese, os recursos tecnológicos devem ser um meio para alcançar um fim.

\section{CONCLUSÃO}

Um dos objetivos da pesquisa consiste em acompanhar as atividades dos engenheiros tendo em vista o que eles dizem sobre a forma como resolvem problemas matemáticos em suas práticas laborais. Nesse sentido, percebeu-se a emergência de um ferramental tecnológico, corroborando as afirmações de Timm (2005). Segundo a autora, o exercício da profissão sofreu mudanças promovidas pelo uso do computador, em especial quando os engenheiros usam softwares de cálculo e de simulação, uma vez que estes aumentam a confiabilidade dos resultados.

A análise dos materiais obtidos a partir das entrevistas também permitiu inferir que recursos como softwares, planilhas e tabelas estão fortemente presentes nas atividades laborais dos entrevistados, pois auxiliam os profissionais em cálculos matemáticos complexos, de difícil solução, que exigem definições de padrões e que demandam tempo na sua resolução. Segundo os profissionais, os softwares reduzem o tempo de elaboração e criação de projetos, possibilitando tempo para desenvolver novas opções para o cliente, e assegurando a ele escolhas que se adéquam às necessidades. Nesse sentido, este estudo comprova as afirmações de Bermudez (1999) que já previa a redução do tempo na criação de novos produtos, caso fossem utilizadas a informática, a automação e a tecnologia. Outra possibilidade descrita pelos entrevistados é o auxílio que estes recursos promovem no que tange ao gerenciamento. Por meio de softwares é possível elaborar planilhas que auxiliam nos processos de tomada de decisão.

O estudo apontou que os profissionais utilizam softwares como Excel, AutoCAD e outros recursos cujos nomes não foram mencionados. De forma similar, o uso de softwares também foi relatado no estudo realizado por Cunha et al (2013, p. 2), na Universidade Federal de Uberlândia, com 16 alunos e 4 professores supervisores na Engenharia Civil, após concluírem o estágio supervisionado. $\mathrm{O}$ estudo teve como objetivo verificar as principais dificuldades, bem como os aspectos positivos do referido estágio. Aludem os autores quanto ao uso de softwares:

Segundo os entrevistados, o software mais exigido pelo mercado aos estagiários foi o Excel, seguido do AutoCAD. Também foram citados o MS Project (software da Microsoft voltado para o planejamento e controle de obras) e o Revit (software da AutoDesk voltado para a criação de maquetes eletrônicas). Percebe-se que esses softwares são de extrema importância para o desenvolvimento das atividades que são confiadas aos estagiários, sendo muitas vezes um pré-requisito para a escolha do candidato à vaga de estágio.

No Vale do Taquari, por meio do estudo de Kipper (2014), identificou-se que, no que concerne à formação do engenheiro de produção, as 
competências determinadas como as mais importantes [na opinião de engenheiros formados e empresários] foram a utilização de indicadores de desempenho e o melhoramento de processos. As principais habilidades elencadas foram a identificação e a resolução de problemas e o trabalho em equipe. Os conhecimentos básicos considerados como essenciais foram a matemática e a expressão oral. $\mathrm{O}$ conhecimento específico tido como o mais importante foi a gerência da produção. Além disso, os entrevistados sugerem a implantação de softwares [no currículo das engenharias] que contribuam para o desenvolvimento das competências e conhecimentos específicos do profissional em questão (KIPPER, 2014, p. 6, grifos dos autores).

A investigação acima mencionada mostra além de outros fatores a importância da implantação de softwares. Cabe comentar que este tema não estava mencionado entre os itens propostos na investigação, mas surgiu da pergunta aberta "que outros conhecimentos os engenheiros deveriam ter além dos elencados nas Diretrizes Curriculares Nacionais?"

Quanto aos profissionais entrevistados nesta pesquisa, cabe citar que eles além de ressaltar a relevância dos recursos tecnológicos também expressam apreensões acerca da sua responsabilidade técnica e afirmaram que as ferramentas tecnológicas não substituem o profissional e demandam uso adequado. Ao revisarem cálculos e projetos em suas atividades cotidianas evitam acidentes que poderiam ser causados por erros de cálculo. Como disse o engenheiro E4, o software não é uma máquina que pensa, mas resolve o problema conforme parâmetros informados.

A partir da importância atribuída dos profissionais aos recursos tecnológicos cabe ao grupo de pesquisa investigar e estudar uma possível reestruturação curricular no que concerne à metodologia de ensino da Matemática, inserindo significativamente o uso dos recursos mencionados: softwares, planilhas e tabelas nas aulas de Introdução às Ciências Exatas, Cálculos I, II, III e Cálculo Numérico.

\section{REFERÊNCIAS}

BARDIN, L.. Análise de conteúdo. São Paulo: Edições 70, 2011.

BAZZO, W. A., PEREIRA, L. T. V.. Introdução à engenharia: conceitos, ferramentas e comportamentos. Florianópolis: Editora da UFSC, 2008.

BERMUDEZ, J. C. M.. A educação tecnológica precisa de uma política. In: LINSINGEN, I. V. et al. (Org.). Formação do Engenheiro: desafios da atuação docente, tendências curriculares e questões da educação tecnológica. Florianópolis: Editora da UFSC, 1999. p. 67-76.

BORGES, M. N.; ALMEIDA, N. N.. Perspectivas para engenharia nacional desafios e oportunidades. Revista de Ensino de Engenharia, v. 32, n. 3., 2013. Disponível em: http://www.abenge.org.br/revista/index.php/abenge/article/view/238/170. Acesso em: 10 out. 2014.

CABRAL, K. M. et al. Análise dos softwares mais utilizados em um curso de engenharia de computação. Anais: XLI Congresso Brasileiro de Educação em Engenharia. Gramado: Associação Brasileira de Educação de Engenharia, 2013. Disponível em: 
<http://www.fadep.br/engenharia-eletrica/congresso/pdf/116936_1.pdf>. Acesso em: 15 out. 2014.

CUNHA et al. Avaliação do estágio supervisionado do curso de Engenharia Civil da UFU. Anais XVIII Encontro Nacional dos Grupos PET, 2013. Disponível em: http://www.portalpet.feis.unesp.br/media/grupos/pet-informatica-recife/atividades/xviiienapet-recife-pe/artigos/AVALIA\%C3\%87\%C3\%830\%20DO\%20EST\%C3\%81GIO\%20 SUPERVISIONADO $\% 20 D O \% 20 C U R S O \% 20 D E \%$ 20ENGENHARIA $\% 20 C I V I L \% 20 D A \% 2$ OUFU.pdf. Acesso em: 15 out. 2014.

FARIAS, R. J. C; OLIVEIRA, A. L.; JÚNIOR, H. A.. Análise de aprendizagem com o uso dos softwares pspice e matlab na disciplina de circuitos elétricos I do curso de Engenharia Elétrica da UNB. Anais XLII Congresso Brasileiro de Educação em Engenharia. Juiz de Fora Associação Brasileira de Educação de Engenharia, 2014.

HATTUM, N.; OLIVEIRA, J. M. N; Williams, B. Investigação em educação em engenharia: um campo emergente em Portugal. Revista de Ensino de Engenharia, v. 32, n. 2, p. 51-62, 2013. Disponível em: <http://www.abenge.org.br/revista/index.php/abenge/ article/ view/ 217/140>. Acesso em: 15 out. 2014.

INFOMAUÁ. Número de engenheiros qualificados no mercado não supre demanda no Brasil. Instituto Mauá de Tecnologia. n. 38. dez. 2012. Disponível em: <http://www.maua.br/infomaua/texto/id/344 z. Acesso em: 15 out. 2014.

KIPPER, D.. Perfil do engenheiro de produção do Vale do Taquari. Trabalho de Conclusão de Curso (Engenharia da Produção). Lajeado: Univates, 2014.

LANKSHEAR, C; KNOBEL, M.. Pesquisa pedagógica: do projeto à implementação. Porto Alegre: Artmed, 2008.

LIMA, T. S.; NETO, G. F.; ARAÚJO JÚNIOR, L. O.. Análise comparativa do uso do software proprietário versus software livre nos cursos de graduação em engenharia. Anais XLI Congresso Brasileiro de Educação em Engenharia. Gramado: Associação Brasileira de Educação de Engenharia, 2013.

LODER, L. L.; BENDER, F. A.. O uso de programas de simulação em cursos de engenharia: possibilidades e necessidades. Anais XLII Congresso Brasileiro de Educação em Engenharia. Curitiba: Associação Brasileira de Educação de Engenharia, 2007.

OLIVEIRA, V. F. et al.. Um estudo sobre a expansão da formação em engenharia no Brasil. Revista de Ensino de Engenharia, v. 32, n. 3, 2013. Disponível em: <http://www.abenge.org.br/revista/index.php/abenge/article/view/235/161>. Acesso em: 15 out. 2014.

PEREIRA, T. R. D. S. et al.. Professores engenheiros ou engenheiros professores? Reflexão sobre o processo de construção da sua prática pedagógica. Anais XLII Congresso Brasileiro de Educação em Engenharia. Juiz de Fora Associação Brasileira de Educação de Engenharia, 2014. 
SILVA, D. da. O engenheiro que as empresas querem hoje. In: LINSINGEN, I. V. et al. (Org.). Formação do Engenheiro: desafios da atuação docente, tendências curriculares e questões da educação tecnológica. Florianópolis: Editora da UFSC, 1999. p. 77-88.

SILVEIRA, D. T.; CÓRDOVA, F. P.. Unidade de Pesquisa Científica. In: GERHARDT, T. E.; SILVEIRA, D. T. (Org.), Métodos de Pesquisa. Porto Alegre: UFRGS, 2009. p. 33-44. Disponível em: <https://www.lume.ufrgs.br/bitstream/handle/10183/52806/000728684.pdf?sequence=1>. Acesso em: 10 dez. 2014.

TIMM, Maria Isabel. Elaboração de projetos como estratégia pedagógica para o ensino de Engenharia (curso à distância de projeto no modelo e-learning-by-doing). Tese de Doutoramento. Programa de Pós-Graduação em Informática na Educação, Porto Alegre, 2005. Disponível em: <http://www.lume.ufrgs.br/bitstream/handle/ 10183/13747/000643927.pdf?sequence=1>. Acesso em: 04 abr. 2014. 